\title{
Technical Analysis of Azimuth Thruster and Conventional Systems
}

\author{
Satriyo Adi Wicaksono*, Deddy Chrismianto, Sahabuddin Sunusi, \\ Herry Boesono and Indradi Setiyanto \\ Coastal Resources Management, Diponegoro University, Semarang, Indonesia; \\ satriyoadi_wicaksono@yahoo.com, deddychrismianto@yahoo.co.id, sahabuddin_sunusi@yahoo.co.id, \\ herryboesono@gmail.com, indradi.fpik@gmail.com
}

\begin{abstract}
Objectives: Supply vessels which are responsible for supporting duties on the offshore industries require a good maneuverability and efficiency. Methods: This research has been carried out by means of a maneuver experiment. According to IMO MSC 137 (76) 2002, there are three kinds of tests: Turning Circle, Zig Zag, and Crash Stop test. Experiments were performed three times for each test. Findings: The samples were taken from vessel TOPAZ JUMEIRAH for representing conventional system and vessel DMS CHALLENGER III for azimuth thruster. The result based on the comparative graphs and tables showed that the vessel which was installed with azimuth thruster had a better maneuverability and low fuel consumption. Application: Now, azimuth thruster is recommended for giving service on the offshore industry.
\end{abstract}

Keywords: Azimuth Thruster, Conventional System, Offshore Industries, Ships Maneuverability, Supply Vessel

\section{Introduction}

Offshore industry demands a strong shipping fleet to meet the logistics needs of goods and people movement from one place on the mainland to reach another place on the sea or offshore and vice versa. A strong shipping fleet is directed to its ships. The ship is operated by experienced navigators; in this case, the master and crew who operate ships in the area of oil drilling off the coast of Qatar. The ability to take maneuver of a ship is indispensable when operating in waters, especially the entry and exit areas of offshore oil drilling in Qatar. But in ships with conventional systems, the maneuver is determined by the performance of the rudder, sea conditions, and the shape of the ship itself. For example, the vessel named TOPAZ JUMEIRAH that uses a conventional system works as an Offshore Support Vessel Al-Shaheen Oilfield, Qatar, showing the results that the motion is less than optimal, especially in conditions of oilfield by the number of the platforms and the distance adjacent to each other. This has implications for the duration and ship operation which will have an impact on operational costs. To overcome this, technology related to the navigation of the ship is needed. The application of technology and control of ships using the azimuth thruster with fixed propeller and thrust capability of the propeller which can rotate $360^{\circ}$ indicates that the performance of the maneuver become easier.

DMS CHALLENGER III as Multi Purpose Support Vessel or Platform Support Vessel which has been fitted with the azimuth thruster works as the supporting vessel in the oil drilling operations. It accommodates the whole treatment of crude oil rig or platform, carries out the logistics and all mining equipment, and also accommodates and facilitates the mobilisation of the workers in the area of offshore oil drilling in Al Idd AshSharqi or PS-1 Oilfield, Qatar. In this case, the mining contractor company Occidental Petroleum of Qatar Limited as the PS-1 Oilfield operator desperately needs ships with an easier operation.

*Author for correspondence 
Field observations through trial maneuver on board with regard to the problem as described in the background of this research resulted in restrictions discussion organised into formulating research problem as follows:

1. Are there any differences in specifications with the ship propulsion azimuth thruster compared with conventional systems?

2. What are the technical advantages and disadvantages of azimuth thruster usage compared with conventional systems?

This study is to assess and analyse the differences in specifications with the ship propulsion azimuth thruster than conventional systems as well as reviewing and analysing the technical advantages and disadvantages of using azimuth thruster with conventional systems. This research activity is also expected to provide knowledge and understanding more specifically the ship propulsion system with azimuth thrusters and conventional systems and provides an overview difference ability of the motion of the vessel based on the experimental method, thereby answering the fact that according to the conditions in the field, it becomes an input in learning if the movement of ships' azimuth thruster and conventional systems, both weaknesses and superiority, understand the ability if the movement of ships with the azimuth thruster becomes easier, effective, and efficient which can recommend ship propulsion system with azimuth thruster in the present and the future, both in the area of oil drilling off the coast of Qatar and elsewhere.

\section{Literature Survey}

\subsection{Azimuth Thruster}

Ships with azimuth thruster or often known as ASD (Azimuth Stern Drive) are equipped with two engines at the stern and capable of producing a $360^{\circ}$ direction of rotation and kick or kick with force propeller thrust the same in all directions. Advantages include electricity being more efficient, better use of spatial ship, and lower maintenance costs. .1 Although there are various names for this type of tugs, all the tugs with ASD thrusters are operating in many ports worldwide. They started using the ASD Tug mainly to push and pull the vessel to be docked or out of the dock, Single Buoy Mooring (SBM), Floating Storage Offloading (FSO), or other offshore facilities. Remote control or automatic control of the azimuth propeller on ships of this type is located on the bridge. The control speed, direction of the kick propeller, and coupling/clutch are controlled using an electronic device, where each manufacturer has a model and its characteristics, although the control system and the arrangement of the propellers for thrust are expected to be similar.

The basic idea behind the making of the azimuth with propellers can rotate $360^{\circ}$, then made omni-directional vertical axis to control the thrust. It is an advantage of manoeuvre ships fitted with azimuth thruster. It also eliminates the need for a reverse gear wheel and the rudder is used in a conventional system that serves as a reduction gear as the car. Unlike the propeller in conventional systems, azimuth thruster manufactured by different companies is called by different names. For example, the unit driving omni-directional Z-drive Rudder Propeller, although the brand name manufacturers such as Schottel, Ulstein Rolls-Royce, Steerprop, Niigata and Duckpeller often used as a generic label for all drivers of azimuth. $\underline{2}$ Azimuth thruster using a conventional propeller is mounted inside the nozzle which can be driven and rotated a full $360^{\circ}$ to provide a boost in any direction without the need for a rudder. The arrangement of this kind is more popularly known as the " $\mathrm{Z}$ " Drive (see Figure 1); this designation came from the shape of the configuration of the drive shaft in the same direction against the machine horizontally, vertically towards the hull, and then horizontally on the vane so as to form a

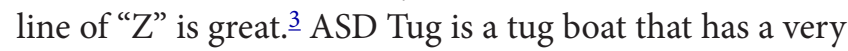
good performance, is responsive and agile, with powerful movement exercise. $\underline{4}$

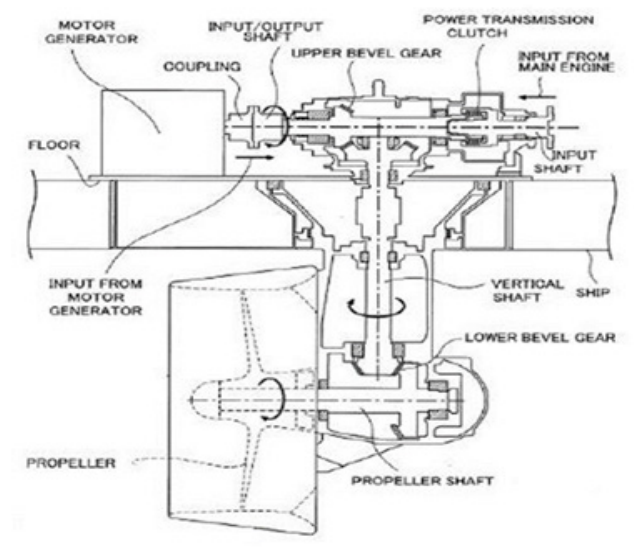

Figure 1. Installation of Azimuth thruster. 
The use of an electric motor or diesel propulsion ranging from 5 to $25 \mathrm{KW}$ replaced the use of propeller shaft and a conventional rudder. Technology makes it possible to place the propeller thrust at the optimal water flow area (hydrodynamically optimised). Thrust propeller of Azimuth Propeller is adopted by placing the electromotor in the thrust and the outside hull. There are three main topics, namely, fixed thrust propulsion thruster or fixed pitch propeller, azimuth thrust, and Contra-Rotating Propeller. 5 , Azimuth thruster is a system where the ship propulsion propeller - propeller or propeller and shafting system - lies in a sheltered thruster construction inside a tunnel which is attached to the ship hull construction. Construction azimuth thruster has a vertical axis so that the propeller on the system can perform a horizontal rotational movement. It makes the azimuth thruster provide advantages in terms of processing motion of the ship. Azimuth thruster also has the ability to kick propeller drive as far as $360^{\circ}$, so it can quickly change the ship's bow as needed. Then, the azimuth thruster, especially on the ship DMS CHALLENGER III, did not use a rudder for manoeuvring the vessel. $\underline{7}$

\subsection{Conventional System}

Ships with a conventional system (see Figure 2) that use a rudder has some shortcomings in the process of motion, such as when the ship is doing the turning circle, the hull will be spinning and turning in a circle diameter or the circle of ship generated track is too large. These losses can occur if the condition is maintained; the time required to return to the original direction becomes longer. Then when the ship did crash stop test or tests dismissal vessel suddenly, crash stop time or the time it takes from when the ship at full speed and the highest power, a moment later the ship's engine in a position full retreat until the ship actually stopped longer, making it less efficient to prevent impingement. $\underline{8}$

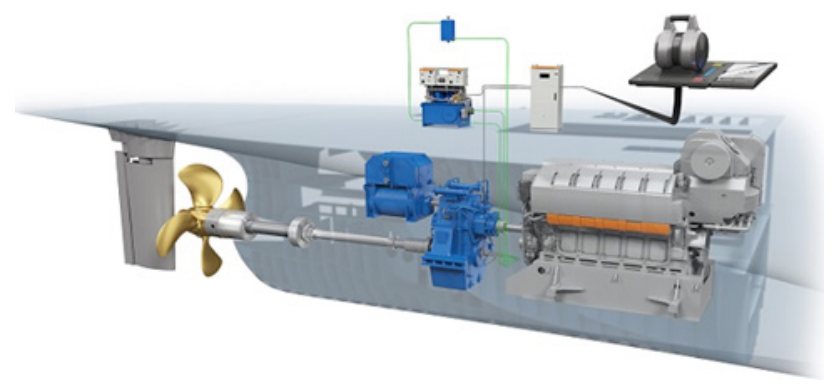

Figure 2. The conventional propulsion system.
The vanes are designed in a manner such that, if the cutting blades in the radial random radius from the centre, then cut the propeller blades will have a certain tone (the amount depends on how crooked is along the axis connecting). If the radius variation of the cut parts, rotating blades also vary from root to tip. This makes it clear that every part of the propeller has a certain tone. Vane roots will have a different tone from the propeller tip.

\subsection{Standards in the Ship Maneuverability}

The procedure used to determine the ability of ships manoeuvre with azimuth thruster and conventional system,,-2 referring to the standard regulations ship navigation capabilities recommended by the International Maritime Organization (IMO), is the resolution MSC137 (76) annex.6 dated December 4, 2002 and applied since January 1, 2004, which is an amendment to the resolution of the previous resolution A.751 (18) on the standard manoeuvrability of the ship. $\underline{10}$ Standard rules referred to herein are based on the understanding that the ability to manoeuvre the ship can be evaluated based on the characteristics of the test manoeuvre as usual or conventional manner, where the vessel in question is a ship that has a length of 50 meters or more (except tankers and gas carriers) using the propulsion and steering system, the conventional ship thrust generated by the propeller driven by the propeller shaft. Analysis on ship's manoeuvre performance, the test manoeuvre both towards portside and starboard should be carried out with the conditions of the test carried out in deep water or unrestricted water, water conditions or a calm environment, the condition of full laden (suit summer load line), even keel, steady approach during the speed test. IMO has recommended some standard criteria for the manoeuvrability of the ship. Such criteria must be met by a vessel when operating in deep water or in restricted waters or operating around the harbour or in shallow waters. For more details see the following Table 1 as follow:

Table 1. Standard of ship maneuverability

\begin{tabular}{|l|l|l|}
\hline Ability & Test & Criteria \\
\hline $\begin{array}{l}\text { Turning } \\
\text { ability }\end{array}$ & $\begin{array}{l}\text { Turning test with } \\
\text { max. Rudder } \\
\text { angle }\left(35^{\circ}\right)\end{array}$ & $\begin{array}{l}\text { Advance }<4,5 \mathrm{~L} \\
\text { Tactical diameter }<5,0 \mathrm{~L}\end{array}$ \\
\hline $\begin{array}{l}\text { Initial } \\
\text { turning } \\
\text { ability }\end{array}$ & $10^{0} / 10^{0}$ Z-test & $\begin{array}{l}\text { Distance ship run before } \\
2^{\text {nd }} \text { rudder execution }< \\
2,5 \mathrm{~L}\end{array}$ \\
\hline
\end{tabular}




\begin{tabular}{|l|l|l|}
\hline $\begin{array}{l}\text { Stopping } \\
\text { ability }\end{array}$ & $\begin{array}{l}\text { Stopping test or } \\
\text { crash-stop test by } \\
\text { full astern }\end{array}$ & Track reach $<15 \mathrm{~L}$ \\
\hline & & $1^{\text {st }}$ Overshoot \\
& $<10^{0}(\mathrm{~L} / \mathrm{U}<10$ \\
& $<(5+0,5(\mathrm{~L} / \mathrm{U}))^{0}(10 \mathrm{~s}<\mathrm{L} /$ \\
Course- & & $\mathrm{U}<30 \mathrm{~s})$ \\
keeping & & $<20^{0}(30 \mathrm{~s}<\mathrm{L} / \mathrm{U})$ \\
and yaw- & $10^{0} / 10^{0}$ Z-test & 2 nd Overshoot \\
checking & & $<25^{0}(\mathrm{~L} / \mathrm{U}<10 \mathrm{~s})$ \\
ability & & $<(17,5+0,75(\mathrm{~L} / \mathrm{U}))^{0}(10 \mathrm{~s}<\mathrm{L} /$ \\
& & $\mathrm{U}<30 \mathrm{~s})$ \\
& & $<40^{0}(30 \mathrm{~s}<\mathrm{L} / \mathrm{U})$ \\
\hline
\end{tabular}

(Source: IMO MSC 137 (76) 2002)

\section{Methods}

This research uses descriptive method by comparing the technical capabilities of conventional system and azimuth thruster through manoeuvre experiments. In carrying out this study, researchers compiled following research framework (see Figure 3):

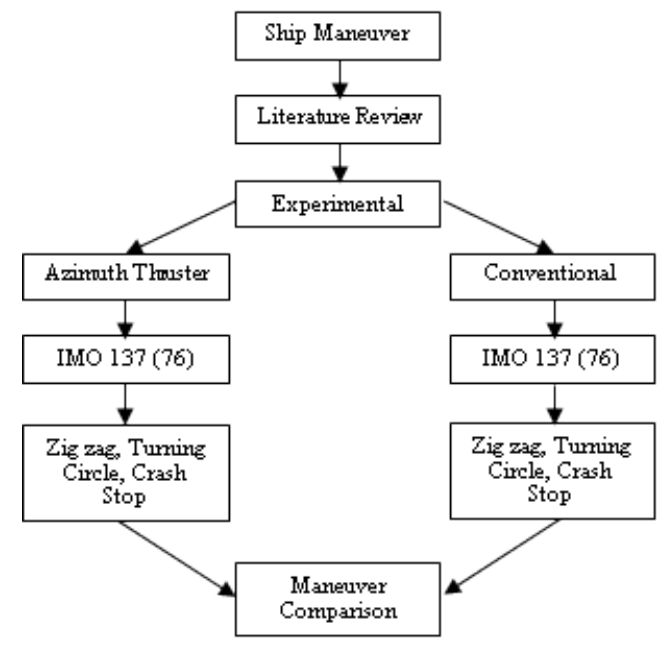

Figure 3. Framework drawing: author.

\subsection{Turning Circle Maneuver}

Turning Circle implement with speed full ahead and the steering distorted. Then keep the rudder make the ship rotates $360^{\circ}$ until it returns to its original heading. According to IMO MSC 137 (76) 2002, turning circle test plan shown as follow (see Figure 4):

\subsection{Zig Zag Maneuver}

Zig Zag Manoeuvre is done with full ahead. The wheel is placed $20^{\circ}$ to the starboard side or to the port side until

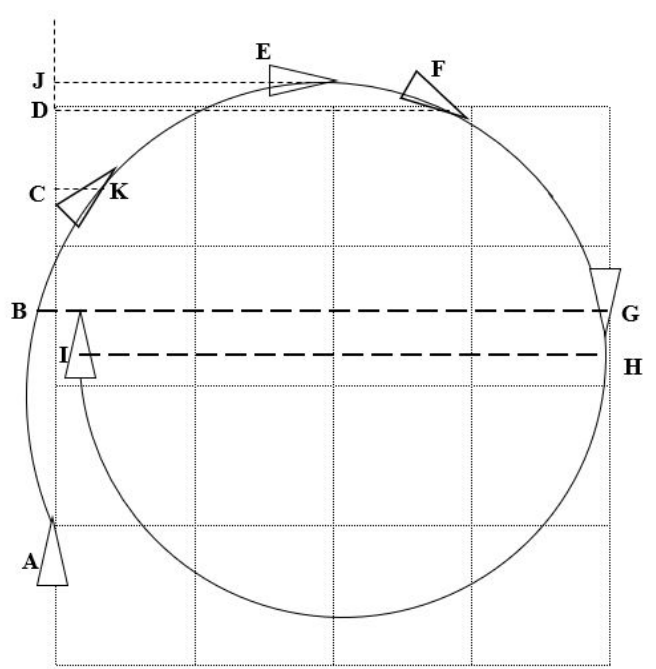

Figure 4. Turning circle test source: IMO MSC 137 (76) 2002, drawing: author.

the heading turned $20^{\circ}$ and $20^{\circ}$ steering wheel placed to the port side or to the starboard side until the heading turned $20^{\circ}$ and $20^{\circ}$ steering wheel again placed to the starboard side or to the port side until the vessel's heading back to its original heading. This movement measure distance and time. According IMO MSC 137 (76) 2002, zig zag test plan shown as follow (see Figure 5):

\subsection{Crash Stop}

Crash stop used in the experiment calculate the result of emergency astern and emergency ahead. Emergency astern carried out with engine full ahead, stop and then full astern until the ship stops in the water and will move backward. This is done to determine the head reach with

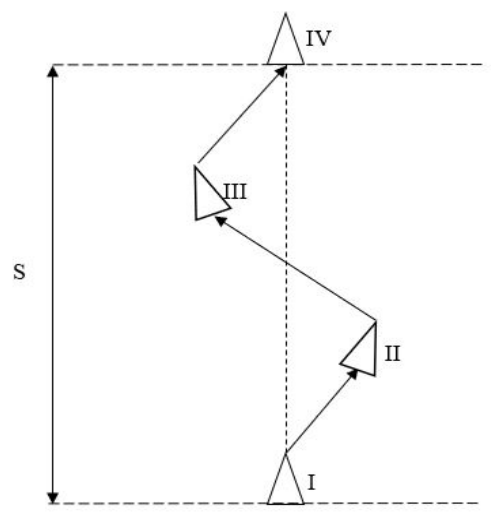

Figure 5. Zig zag test source: IMO MSC 137 (76) 2002, drawing: author. 
time and distance. According to IMO MSC 137 (76) 2002, crash stop plan is shown in Figure 6.

This experiment is carried out by the researcher in the Qatar Water (see Appendix 1). We recorded the coordinates, latitude and longitude, when the vessel was manoeuvring both turning circle, zig zag, and crash stop test. Then we converted the distance in meter units. Not only the coordinates, we also recorded the vessel's time during the experiments.

\section{Result and Discussion}

\subsection{Turning Circle}

The results of numerical simulation of ship movements when turning circle test with a slope angle of the conventional system and azimuth thruster about $20^{\circ}$. Manoeuvring experiments using conventional systems and azimuth thrusters on first, second, and third trials by conversion of the coordinates on Global Positioning System (GPS) device produce Tactical and Final diameter as shown in Table 2 as follows:

Finals and tactical diameter difference between the conventional and the azimuth thruster look quite significant (see Figure 7). This showed that the use of azimuth thruster produces tactical and final diameter smaller than conventional system. Impairment finals and tactical diameter of about $85 \%$ after using azimuth thruster.

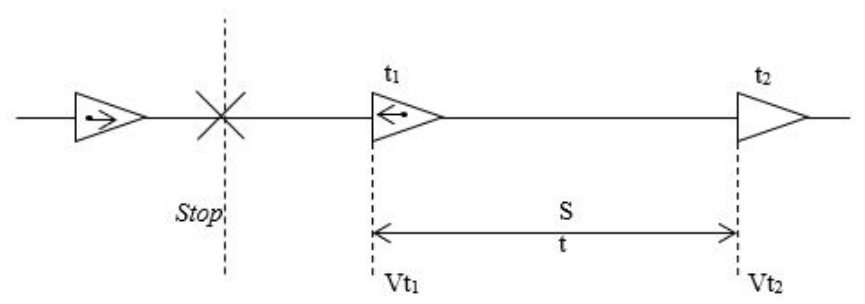

Figure 6. Crash stop test source: IMO MSC 137 (76) 2002, drawing: author.

Table 2. Average diameter

\begin{tabular}{|l|l|l|}
\hline $\begin{array}{l}\text { Type of } \\
\text { propulsion }\end{array}$ & $\begin{array}{l}\text { Tactical diameter } \\
(\mathbf{m})\end{array}$ & $\begin{array}{l}\text { Final diameter } \\
\text { in }(\mathbf{m})\end{array}$ \\
\hline Azimuth thruster & 111,3 & 107,7 \\
\hline $\begin{array}{l}\text { Conventional } \\
\text { system }\end{array}$ & 752 & 697 \\
\hline
\end{tabular}

$\mathrm{m}=$ meter.

(Analyze Primary Source, 2018)

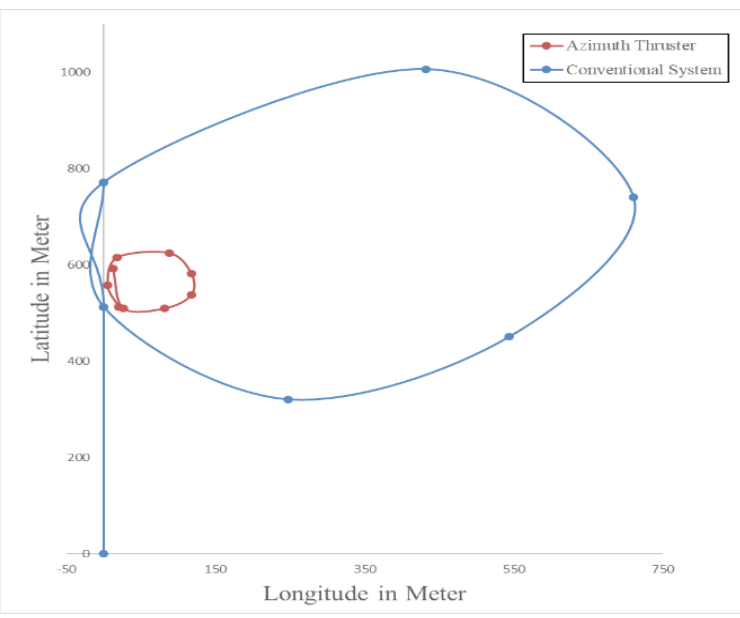

Figure 7. Comparison of turning circle (Analyze Primer Source 2018).

\subsection{Zig Zag Manoeuver}

Experiment with the vessel's ability of azimuth thruster and the conventional system through conversion results in a graph of GPS coordinates as follows:

From the graph (see Figure 8), we know when the vessel takes zig zag manoeuvre in order to alter her course by using azimuth thruster, it will appear a taper arc then the vessel use the conventional system. Not only have taper arcs, but also the vessel who installed with azimuth thruster takes short distance to reach the point with same heading when she is start manoeuvring. It is possible to minimised vessel collide with the jetty and the vessel with vessel.

\subsection{Crash Stop}

After conducting Crash Stop test on 2 types of different propulsion system with timekeeping as follows:

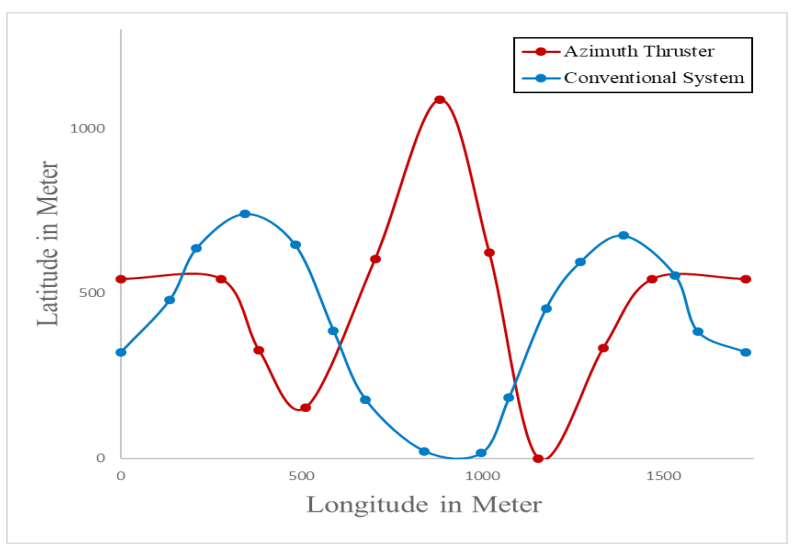

Figure 8. Comparison of Zig zag (Analyze Primer Source 2018). 
Based on Table 3, it can be seen that the Crash Stop time resulted by the azimuth thruster only take 34.6 to 38.1 seconds, whereas the conventional system takes 68.2 to 83.6 seconds. The distance comparison between azimuth thruster and conventional systems can be seen in Table 4.

Based on Table 4, range between the azimuth thruster and conventional systems looks significant. If the average range of azimuth thruster is 164 meters, while the conventional system reaches 354 meters. The azimuth thruster leads a better result because of the distance and the time taken for the crash stop smaller than conventional systems.

In Figure 9, the red arrow indicates that the crash stop through azimuth thruster and the blue arrow indicates vessel which using conventional system. Stopping distance on this figure is converted from meter to cables.

Table 3. Crash stop time

\begin{tabular}{|l|l|l|l|}
\hline $\begin{array}{l}\text { Type of } \\
\text { propulsion }\end{array}$ & $\mathbf{1}^{\text {st }}$ trial (s) & $2^{\text {nd }}$ trial (s) & $\mathbf{3}^{\text {rd }}$ trial (s) \\
\hline Azimuth thruster & 34.6 & 35.2 & 38.1 \\
\hline $\begin{array}{l}\text { Conventional } \\
\text { system }\end{array}$ & 83.6 & 74.2 & 68.2 \\
\hline
\end{tabular}

$\mathrm{s}=$ second.

(Analyze Primary Source 2018)

Table 4. Comparison of crash stop distance

\begin{tabular}{|l|l|l|l|}
\hline Type of propulsion & $\mathbf{1}^{\text {st }}$ trial & $2^{\text {nd }}$ trial & $\mathbf{3}^{\text {rd }}$ trial \\
\hline Azimuth thruster & 161 & 164 & 167 \\
\hline Conventional system & 332 & 354 & 378 \\
\hline
\end{tabular}

$\mathrm{m}=$ meter.

(Analyze Primary Source, 2018)

\begin{tabular}{|l|l|l|l|}
\hline & & 5 & \\
\hline & & 4 & 1,911 \\
\hline & $\begin{array}{l}0,886 \\
36 \mathrm{~s}\end{array}$ & 1 & $75 \mathrm{~s}$ \\
\hline & & 2 & \\
\hline
\end{tabular}

Figure 9. Stopping characteristics (Analyze Primary Source, 2018).

\subsection{Fuel Consumption}

Figure 10 is a comparison of fuel consumption per hour each day in a month. The conventional system adopted by TOPAZ JUMEIRAH and azimuth thruster adopted by DMS CHALLENGER III. Through the trendline, it appears that the longer working hours using a conventional system may need fuel greater than azimuth thruster. Therefore, by using the azimuth thruster fuel oil on board can be saved.

\subsection{Azimuth Thruster Usage Recommendations}

With the results discussed above, the azimuth thruster is reassuring to be able to recommend the use and operation on ships in particular types of ships supply work in the area of offshore oil drilling in Qatar Water, and throughout the world, because with strengths that have very good performance, responsive, agile motion exercise is very powerful and efficient. Convenience of the operator or master of ships with this system to operate it, so it can improve the performance of the vessel and its crew are effective and efficient in the present and the future.

Effective use of azimuth thruster is to increase the speed of the ship and protect the blades from foreign objects. In propeller type this, hydraulic coupling of positive and negative can be used to put it in between the main engine and drive shaft universal joint, and the drive shaft universal joint connected to the transmissionshaped $\mathrm{Z}$ to allow the propeller rotates forward and reverse and improve the efficiency of propulsion vane can be increased by about $15 \%$.

Azimuth thruster using hydraulic propulsion sources and directly drive the propellers via a hydraulic motor. Propellers of this type has the advantage of a compact

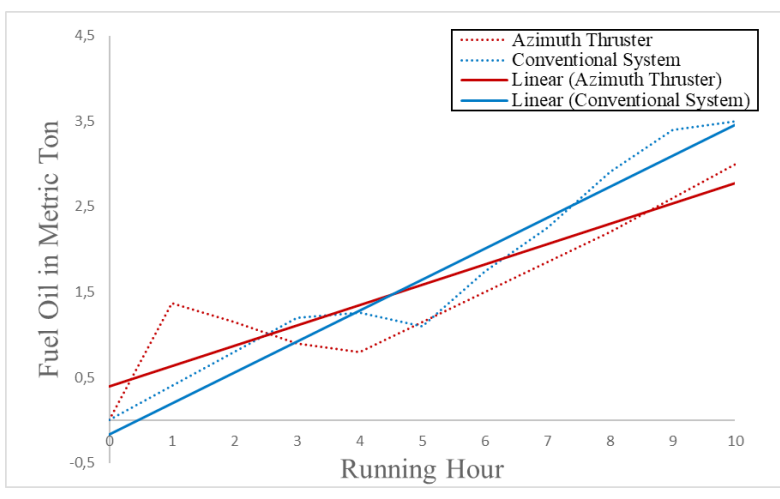

Figure 10. Graph of FO consumption (Analyze Primary Source, 2018). 
structure, installation and simple operation, easy maintenance and low cost, and no longer the period of the manufacturing cycle. In addition, available in different specifications and in accordance with different strengths. On the ship that could be used, there is a simple construction of the vessel.

From today's technology, propulsion and rotation hydraulic vane can be controlled by a digital intelligent control. In addition, through this control mode, the driving and the rotation speed can be continuously changed.

The rotation angle is well controlled and easy to operate, making it easy to interact with the control system for digital communication. In the specific operation, it was realised by using four components of the inverter control, Programmable Logic Controller (PLC), digital angle encoder, and digital flow control valves. According to the programmed control commands, integrated inverter, encoder and integrated digital flow. Parameter control valve status are analysed and rated to issue commands to control the technical parameters, so that the hydraulic vane full rotation can work and operate smoothly. Azimuth thruster with Nozzle is a certain type of propeller used in comparison with others propeller. Vane type has certain advantages in some aspects, so it is beneficial in some industries offshore. Some of the benefits of this thruster are:

1. In shafting arrangement, we can play propulsion. In addition, the propeller's direction at any time can be changed to make the ship turn around, move forward, and backward.

2. The rudder while full rotation, the drive propellers as the steering force. In addition, this type of propulsion has great power; forward and reverse pressure is substantially the same.

3. Treatment propeller can be done without underwater works, installation, and maintenance simple.

4. Thrust's structure is simple, has small volume, and the occupied area is also small, so it can be used flexibly and securely on ecosystems.

5. The electricity supply to the thruster full round from the motor or batteries can be used to improve the efficiency of the propeller, and the savings can also be achieved to extend its service.

\section{Conclusion}

From the discussion in the previous chapter, the researchers conclude that the fundamental difference between the type of propulsion azimuth thruster and conventional system is the thrust's direction can be set up to $360^{\circ}$, when ship manoeuver such as turning circle, zig zag, and crash stop test demonstrate that the ships using the azimuth thruster, her capability to manoeuvre becomes better than vessels with conventional systems. Seen from the results or performance of control and the manoeuvrability of the ships with azimuth thruster can be on ships which work in the Qatar Waters, in order to improve the performance of the vessel, and its crew are effective and efficient in the present and the future.

\section{References}

1. Hydrodynamic aspects of steerable thrusters. [cited 2004 Sep 28]. https://dynamic-positioning.com/proceedings/ dp2004/thrusters_dang.pdf.

2. Propulsion and steering behaviour of a ship equipped with two contra-rotating Z-drives. [cited $2012 \mathrm{Oct}$ ]. https://www. researchgate.net/publication/317350859_Propulsion_ and_steering_behaviour_of_a_ship_equipped_with_two_ contra-rotating_Z-drives.

3. Desai-Patil V, Ayare A, Mahajan B, Bade S. A review of Azimuth thruster. SSRGInt J Mech Eng. 2015;2(10):21-4.

4. Zaraphonitis G, Bitner-Gregersen E,El Moctar O, Guedes Soares C, Papanikolaou A,Shigunov V, et al. Energy efficient Safe Ship Operation (SHOPERA). Transport Res Proc. 2016;14:820-9.

5. Our journey so far. [cited 2018 Sep 17]. http:// food4thoughtfoundation.org/2018/09/17/our-journeyso-far-issue-16/.

6. Wartsila controllable pitch propeller systems.[cited 2018]. https://www.wartsila.com/marine/build/propulsors-andgears/propellers/wartsila-controllable-pitch-propellersystems.

7. Hydrodynamic optimal design of ducted Azimuth thrusters. [cited 2009]. https://www.semanticscholar. org/paper/Hydrodynamic-Optimal-Design-of-DuctedAzimuth-Funeno/f22b3b16ecd56a50208ae6a7890e5e 325200cf8c.

8. Pramudito. Challenges of operations offshore logistics: case study drilling operation offshore oil and gas in Indonesia. In: Proceeding of the national seminar on management of technology XVIII; 2013.P. 1-12.

9. Standardsfor ship maneuverability. [cited 2002 Dec 04]. http://www.imo.org/en/KnowledgeCentre/IndexofIMO Resolutions/Maritime-Safety-Committee-\%28MSC\%29/ Documents/MSC.137\%2876\%29.pdf.

10. Rulesfor classification of highspeed, light craft, and naval surface craft. [cited 2016 Jul]. http://rules.dnvgl.com/docs/pdf/ DNV/RulesHSLC/2016-07/DNV_HSLC.pdf.AAAAAA0 


\section{Appendix}

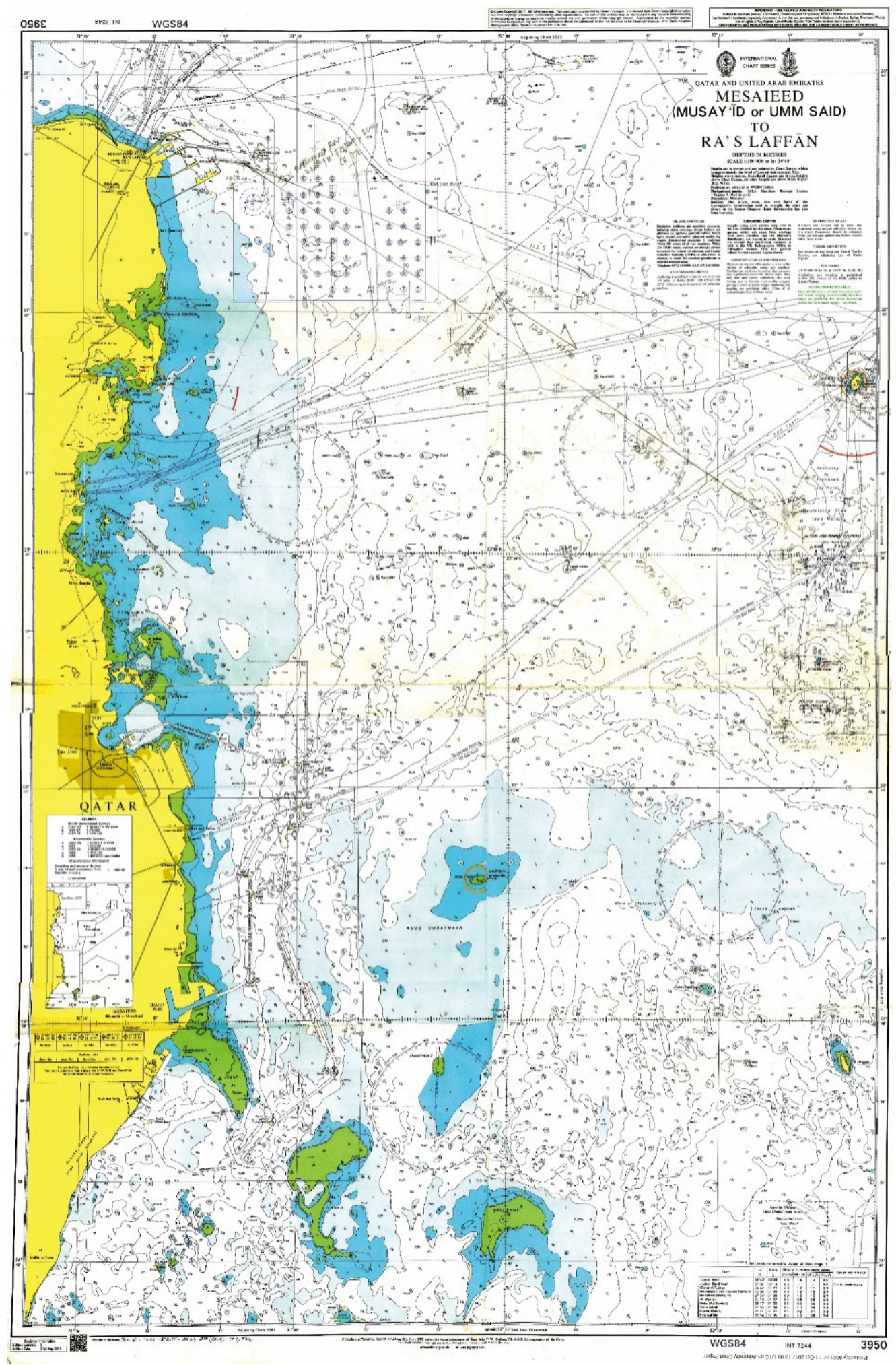

Qatar water maps (Source: BA chart 3950). 